\title{
THE EFFECT OF ESTROGEN ON WATER AND ELECTROLYTE METABOLISM. III. CARDIAC AND RENAL DISEASE
}

\author{
By JOHN R. K. PREEDY AND ELSIE H. AITKEN \\ (From the Medical Unit, The London Hospital, London, E. 1, England)
}

(Submitted for publication August 29, 1955; accepted December 28, 1955)

If the sodium chloride and water retention observed in cirrhosis with ascites after estrogen administration (1) were due to delayed hepatic inactivation of the hormone, and if this were in turn dependent on an impairment of the hepatic circulation rather than on hepatocellular damage, then a similar retention of $\mathrm{NaCl}$ and water after estrogen would be expected in conditions where the hepatic circulation was prominently affected, but hepatocellular damage minimal.

Early cases of constrictive pericarditis and cardiac failure from other causes were selected as fitting most nearly into the above category, and they, together with more advanced cases, were submitted to water and electrolyte balance studies, during which the effects of estrogen administration were noted. Two cases of venous obstruction without cardiac failure were similarly studied for comparison.

Since any changes in $\mathrm{NaCl}$ and water metabolism observed in the above groups might be attributed equally well to delayed renal clearance as to decreased hepatic inactivation of the hormone, the effect of estrogen administration in water and electrolyte metabolism was also studied in primary renal disease, and for this purpose a group of cases with the nephrotic syndrome was selected, and studied as above. Two cases of low plasma albumin edema without renal disease were similarly studied for comparison.

\section{CLINICAL MATERIAL}

1. Constrictive pericarditis ( 7 cases). The cases selected fall into two groups:

(a) Four cases without symptoms, in whom the disease was discovered at routine medical examination for the Armed Forces, or for other purposes (Nos. 8, 9, 52 and 59). There was no detectable ascites in these cases. Liver function tests were normal, except for a raised serum bilirubin (up to $2.5 \mathrm{mg}$. per $100 \mathrm{ml}$.), or a slight excess of urinary urobilinogen in some cases. Liver biopsies in cases 52 and 59 showed minimal focal fibrosis only and no cellular damage. These subjects were ambulant for part of the day during the study.

(b) Three cases with definite symptoms referable to the disease (Nos. 46, 53 and 67). Two cases (Nos. 53 and 67) had had symptoms for several years, and one case (No. 53) had had a partial pericardectomy five years previously, with little relief. One case (No. 53) had ascites at the time of the study, and two cases (Nos. 46 and 67) had a recent history of ascites, but no detectable ascites at the time of the study. Liver function tests were normal except for raised plasma bilirubin levels (up to $2.9 \mathrm{mg}$. per $100 \mathrm{ml}$.). Liver biopsy in case 46 showed slight focal fibrosis and no cellular damage, and in case 53 extensive dense fibrosis without significant parenchymal change. Cases 46 and 67 were partly ambulant, and case 53 at bed rest during the study. Blood urea levels were normal in each group.

2. Cardiac failure (5 cases). Cases in this group were suffering from cardiac disease other than constrictive pericarditis-valvular disease in three cases (Nos. 12, 31 and 32) and of uncertain origin (?arteriosclerotic) in two cases (15 and 47). One case was in her first attack of failure (No. 32), one in her second attack (No. 47) and the remainder had had features referable to cardiac failure for $\mathbf{2}$ to $\mathbf{5}$ years. Liver function tests were normal in all cases except No. 12, where the plasma bilirubin was raised to $2.3 \mathrm{mg}$. per $100 \mathrm{ml}$. Blood urea levels were normal.

3. Venous obstruction (2 cases). One case in this group (No. 28) had superior vena cava obstruction due to a mediastinal gumma (shown at postmortem). There was constant marked edema of the upper part of the body. The other case (No. 68) the inferior vena cava was thrombosed, and there was marked edema of the lower half of the body, which rapidly subsided with rest in bed, accompanied by a $\mathrm{NaCl}$ and water diuresis. There was no evidence of cardiac, renal or hepatic disease in either case.

4. Nephrotic syndrome (5 cases). In four of the cases in this group (Nos. 30, 37, 51, 57) the syndrome was caused by chronic glomerulo-nephritis and in the fifth (No. 54) by primary renal amyloid disease. There was no evidence of cardiac or hepatic disease. Duration of the edema was 1 to 18 months, except in case 30 where it had been present for 5 to 6 years. There was no arterial hypertension in any case. Blood urea levels were either normal or somewhat raised. Ascites was present in two cases (No. 37 and 51). Conventional renal function tests either yielded normal results, or indicated some impairment of function.

5. Low plasma albumin edema (2 cases). One case (No. 69) in this group had chronic edema of the legs, associated with a constant plasma albumin of between 2.4 and $1.7 \mathrm{~g}$. per $100 \mathrm{ml}$. over a period of years, which 


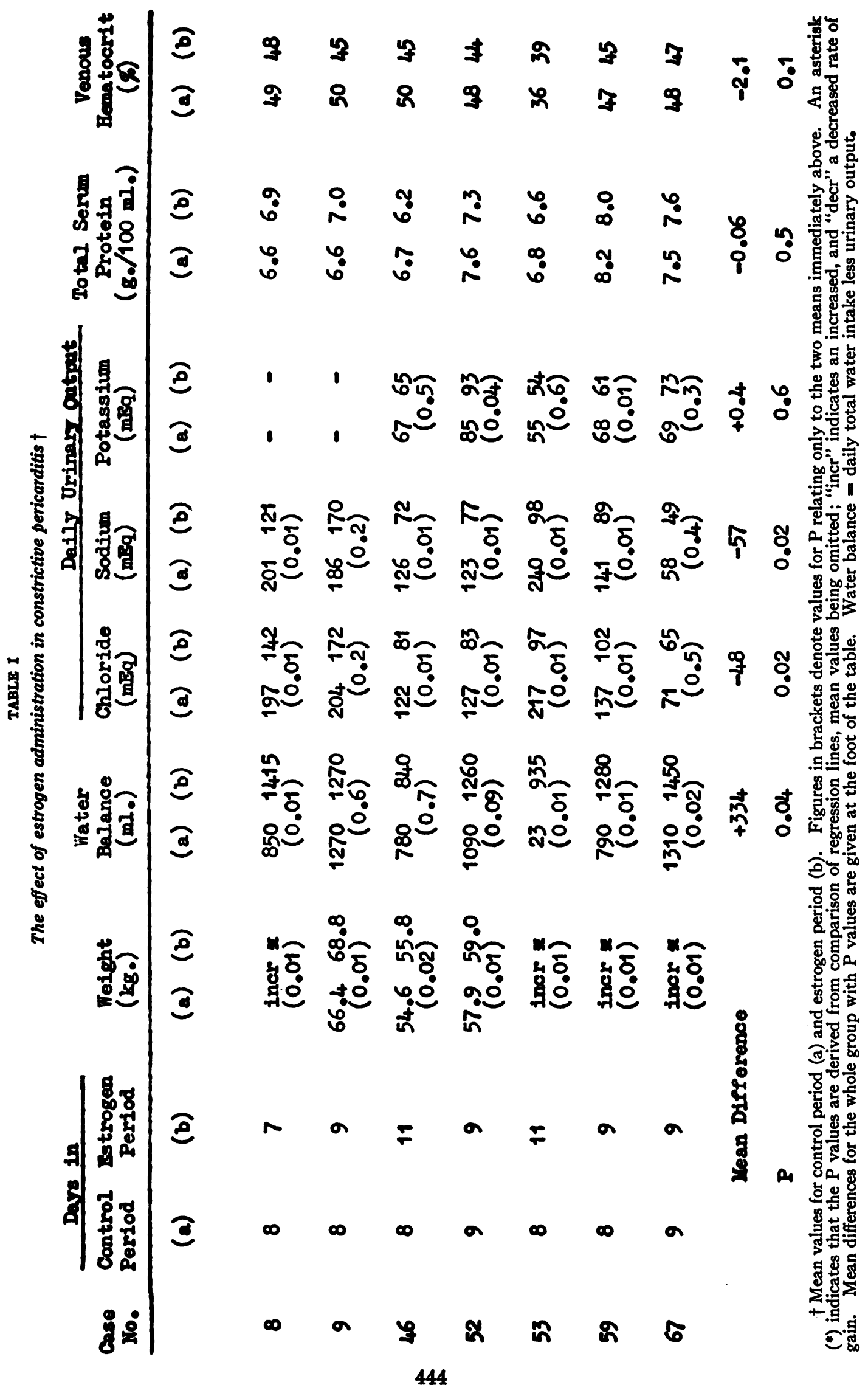


was unexplained. In the other case (No. 77), the low plasma albumin levels were due to inadequate dietary intake of protein, partially remedied during the course of the study by a high protein diet.

The balance study, estradiol dosage, estimation and methods and presentation of results are as previously described (2).

\section{RESULTS}

\section{Constrictive pericarditis (Table I)}

Weight. Group mean difference between control and estrogen periods was not calculated due to the proportionately large number of weight trends during the control period. There was a significant weight gain following estrogen administration in each of the 7 cases studied.

Water balance. There was a group mean difference between periods of $+334 \mathrm{ml}$. which was of borderline significance $(P=0.04)$. There was a significant mean increase in water balance in 4 of the 7 cases studied.

Daily urinary output. $\mathrm{Cl}$ and $\mathrm{Na}$. There was a significant mean decrease in $\mathrm{Cl}$ and $\mathrm{Na}$ output

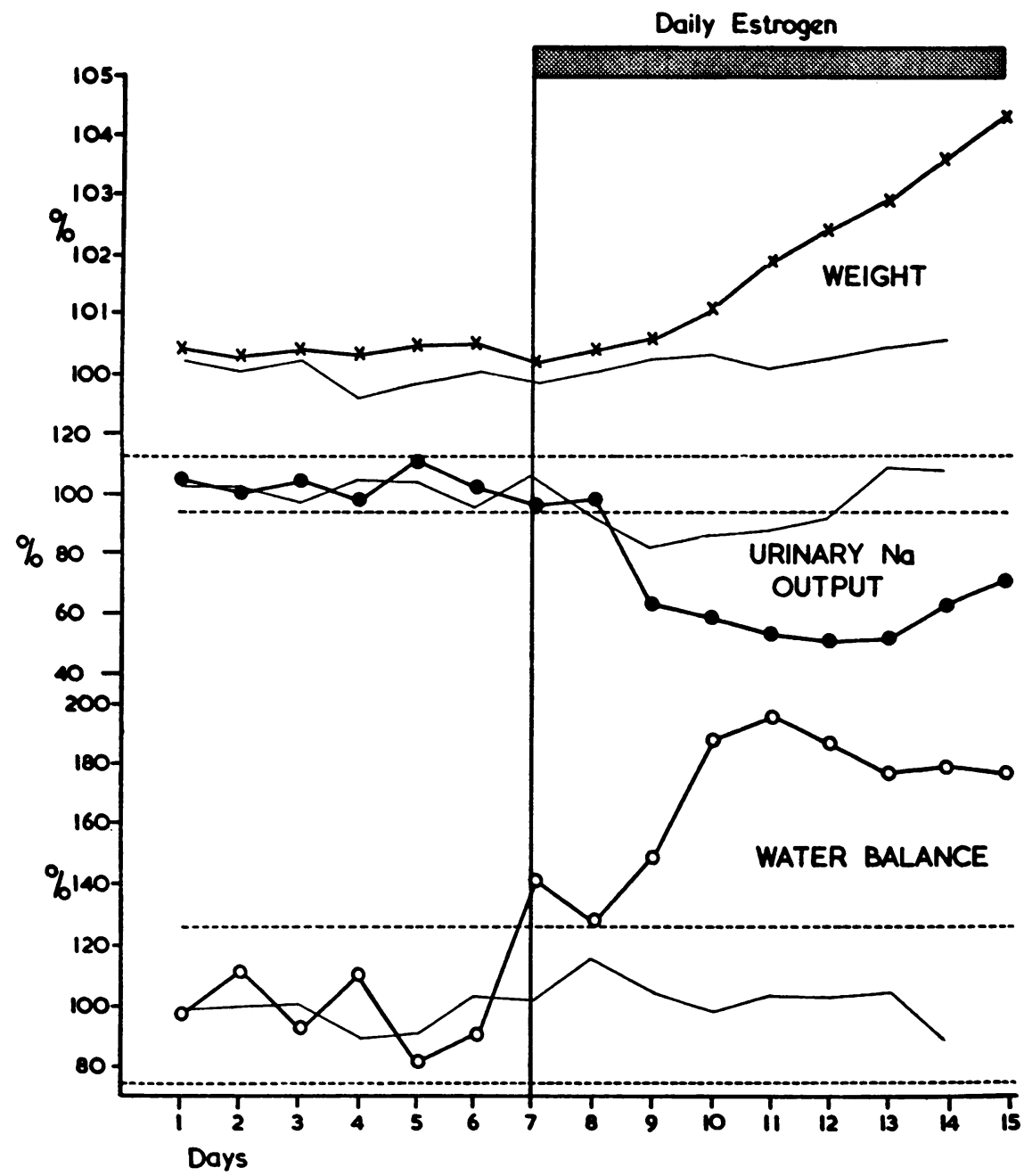

Fig. 1. The Effect of Estrogen Administration on DaIly Weight, Urinary Sodium Output and Water Balance in Constrictive Pericarditis

Control period, days 1 to 6 ; estrogen period, days 7 onwards. Each point represents the daily average for the group expressed as a percentage of the control period mean. Water balance $=$ daily total water intake less urinary output. Horizontal interrupted lines denote the 95 per cent confidence limits for the control period for each class of observation. Results in the normal group are inserted for comparison (continuous line). 
following estrogen, group mean difference being $-48 \mathrm{mEq}$. and $-57 \mathrm{mEq}$. respectively. A significant decrease in $\mathrm{Cl}$ and $\mathrm{Na}$ output occurred in 5 of the 7 cases.

$K$. Estrogen administration had no effect on $\mathrm{K}$ output as a group. There was a small but significant decrease in case No. 59 , and a small increase in case 52 , which was of borderline significance.

Total serum protein and venous hematocrit were not significantly affected.

Plasma $\mathrm{Cl}$ and $\mathrm{Na}$. No significant difference in these levels was observed (group mean differences $-0.4 \mathrm{mEq}$. per L. $[\mathrm{P}=0.8]$, and $+0.4 \mathrm{mEq}$. per L. [P $=0.9]$ respectively).

Figure 1 shows that there is a marked and sustained decrease in average daily urinary $\mathrm{Na}$ output accompanied by an equally marked increase in average daily weight and water balance following the administration of estrogen. The above changes were accompanied by a significant decrease in $\mathrm{Na} / \mathrm{Cl}$ ratio during the estrogen period (Figure 2).

By calculation, there was an average gain in weight during the estrogen period of $2.6 \mathrm{~kg}$. accompanied by an average apparent retention of $315 \mathrm{mEq}$. Cl., $377 \mathrm{mEq}$. $\mathrm{Na}$ and $1970 \mathrm{ml}$. water. These figures are approximately in the proportion expected if the gain in weight were due to increase in extracellular fluid (ECF) volume. (Case No. 53 where there was an obvious $\mathrm{NaCl}$ and water diuresis during the control period was not included in this calculation.)

\section{Cardiac failure (Table II)}

Weight. There was a significant group mean difference between periods of $+0.82 \mathrm{~kg}$. In individual cases, there was a significant increase in weight in two cases (Nos. 31 and 47), and an increase of borderline significance in one case (No. 12).

Water balance. There was a group mean increase following the administration of estrogen of $256 \mathrm{ml}$. which was of borderline significance. A significant increase was observed in two individual cases only (Nos. 12 and 31 ).

Daily urinary outputs. $\mathrm{Cl}$ and $\mathrm{Na}$. There was a significant group mean difference between periods of $-23 \mathrm{mEq}$. $\mathrm{Cl}$ and $-28 \mathrm{mEq}$. $\mathrm{Na}$. In individual cases, a significantly decreased output of $\mathrm{Cl}$ following estrogen was observed in two cases (Nos. 31 and 47), and a decreased output of borderline significance in two (Nos. 12 and 32). A significantly decreased output of $\mathrm{Na}$ was observed in all cases except No. 15.

$K$. There was no significant change in two of the three cases, and in one case (No. 32) there was a small increase of borderline significance.

$P O_{4}$. Of the three cases, there was no significant difference between periods in No. 31, but a small but significant decrease in cases 32 and 47 .

Total serum protein. The mean difference between periods was non-significant.

Venous hematocrit. There was a highly significant group mean decrease in the volume of packed cells $(\overline{\mathrm{d}}=-5$ per cent, $\mathrm{P}=0.02)$. This

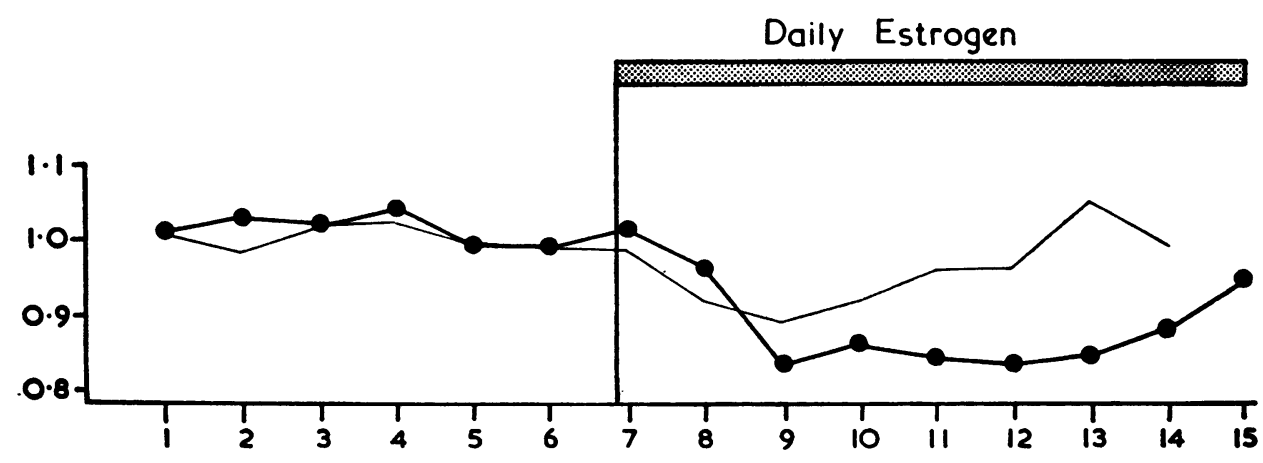

Days

Fig. 2. The Effect of Estrogen Administration on the Daily Urinary Na/Cl Ratio in Constrictive Pericarditis

Control period, days 1 to 6 ; estrogen period, days 7 onwards. Each point represents the daily average for the group. Results in the normal group are inserted for comparison (continuous line). 


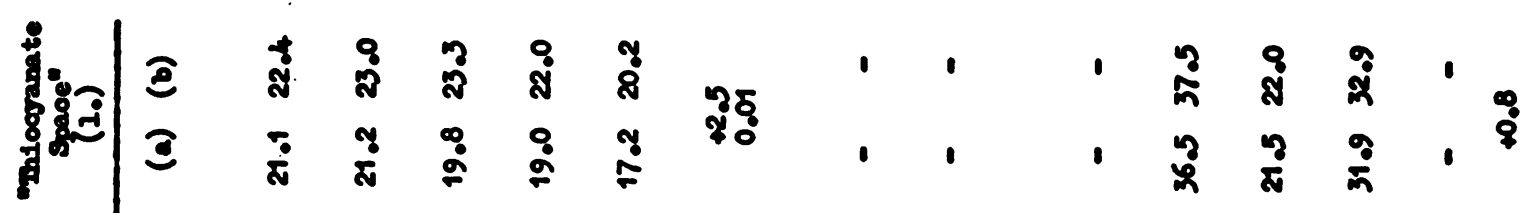

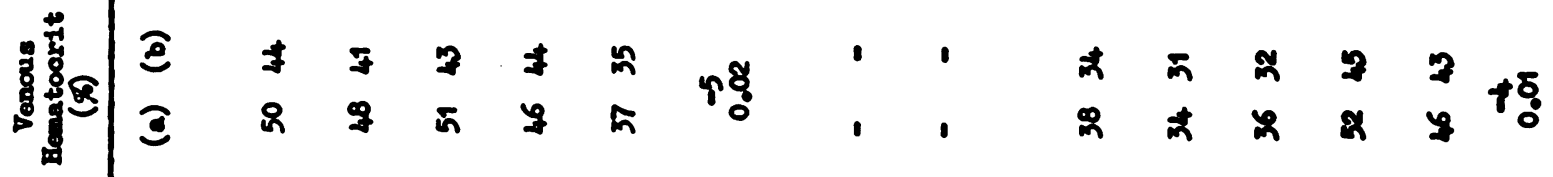

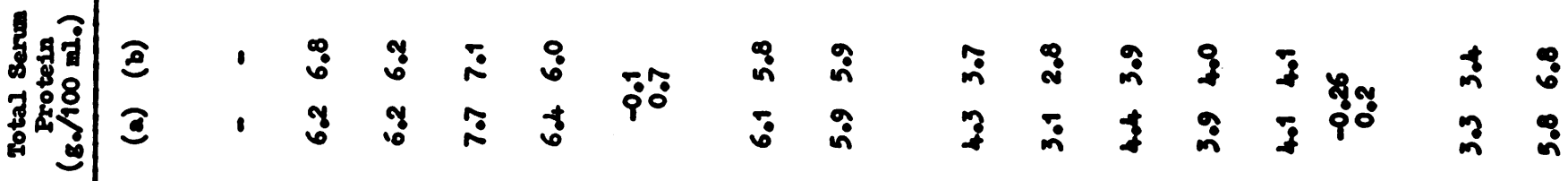

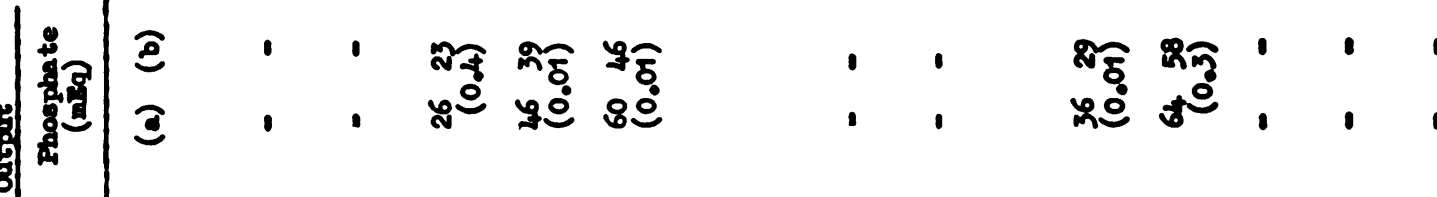

[1]

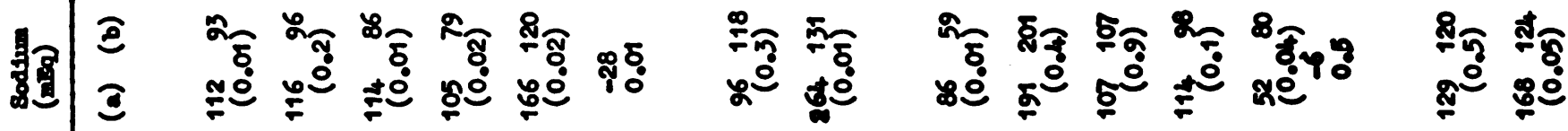

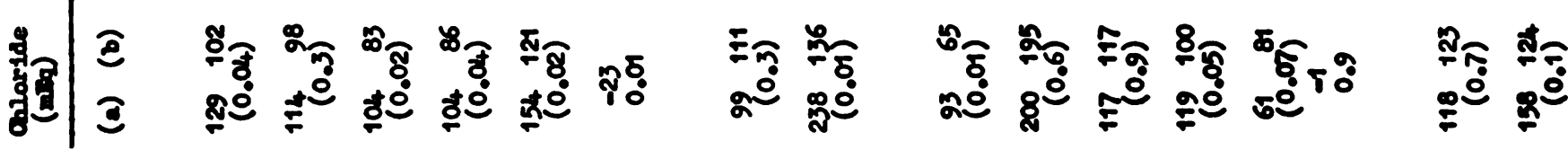

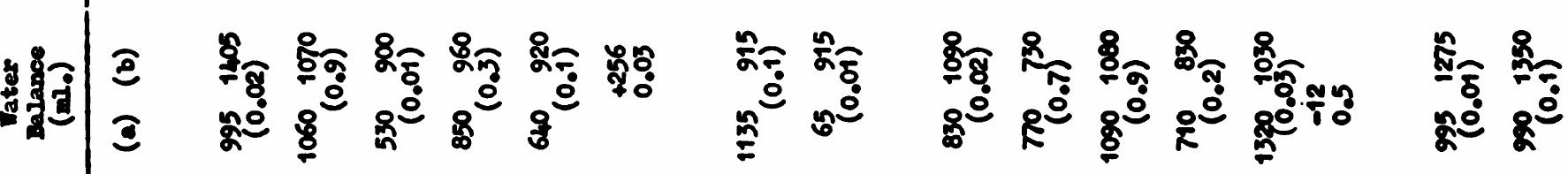

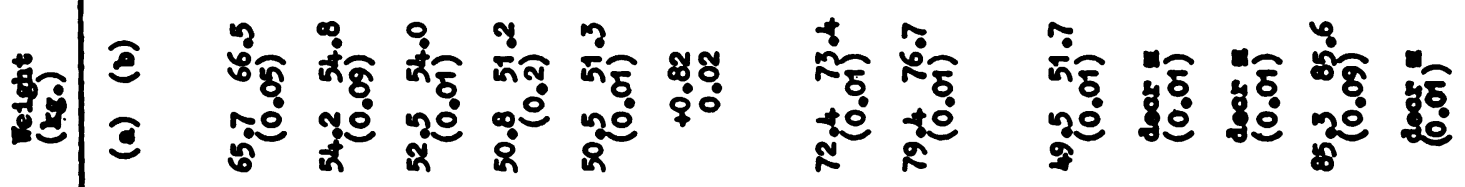
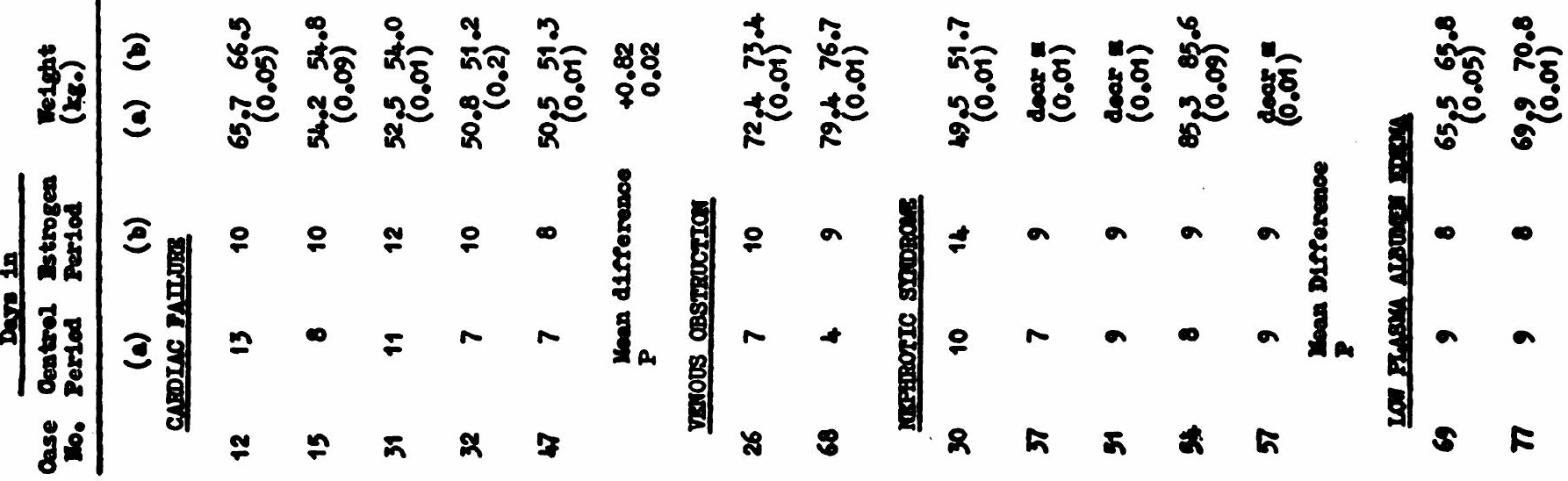


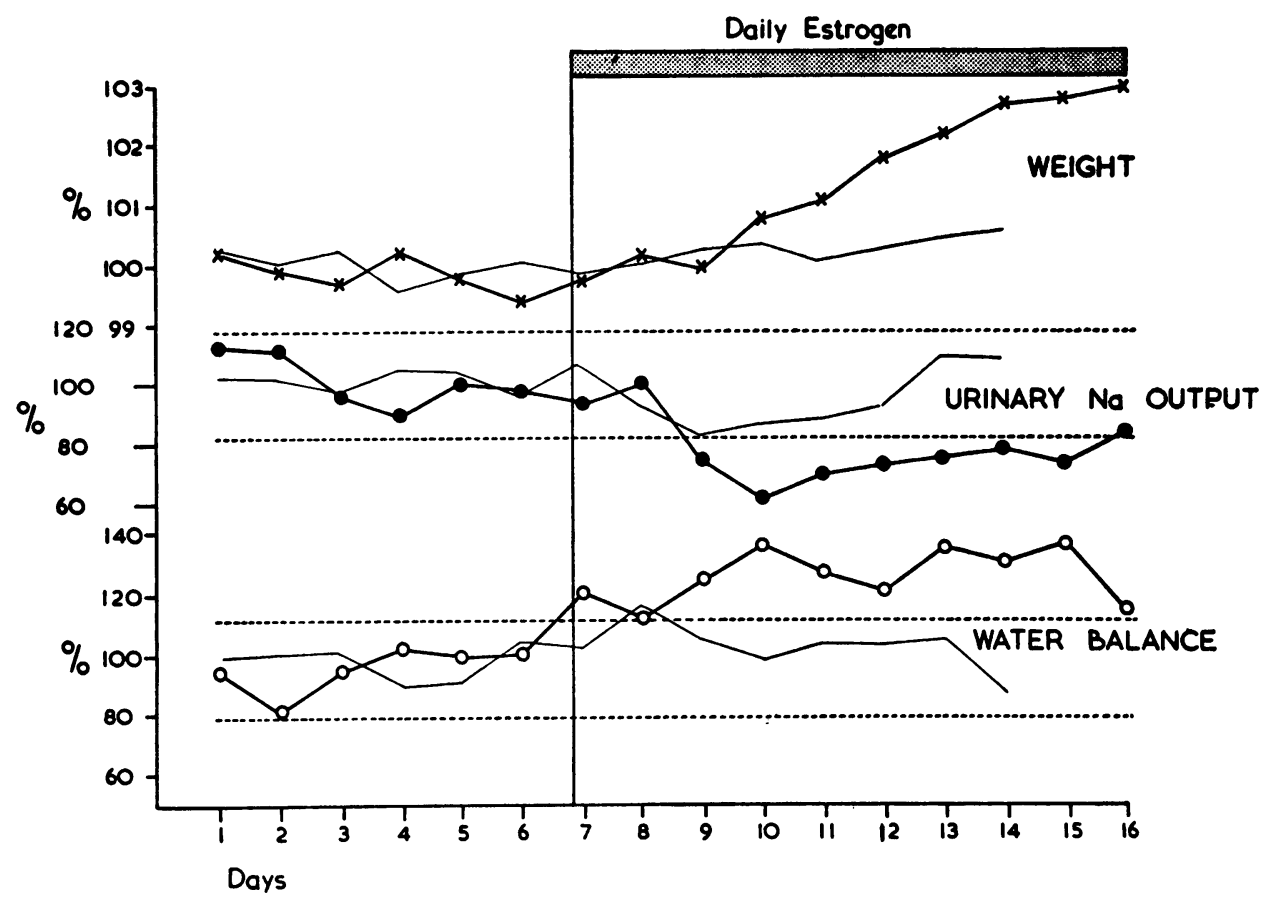

Fig. 3. The Effect of Estrogen Administration on Daily Weight, Urinary Sodium Output and Water Balance in Cardiac Failure

See footnote, Figure 1.

represents a mean decrease below control values of approximately 11 per cent.

Plasma $\mathrm{Cl}$ and $\mathrm{Na}$. There was no significant difference between periods ( $\overline{\mathrm{d}}=+0.4 \mathrm{mEq}$. per L. in each case, $P=0.7$, and 0.8 respectively).

Thiocyanate space. There was a group mean increase following estrogen of $+2.5 \mathrm{~L}$. which was significant.

Figure 3 shows the significant increase in average weight and water balance, and decrease in average urinary $\mathrm{Na}$ output which occurred during the estrogen period.

By calculation there was an average weight gain during the estrogen period of $2.3 \mathrm{~kg}$. and an apparent retention of $221 \mathrm{mEq}$. Cl., $282 \mathrm{mEq}$. $\mathrm{Na}$ and $2170 \mathrm{ml}$. water. The thiocyanate space was significantly increased by a mean of $2.5 \mathrm{~L}$. These figures are in the proportion expected if the gain in weight were chiefly due to an increase in ECF volume.

\section{Venous obstruction (Table II)}

Group analysis was not attempted. In case 26 , there was a significant increase in weight during the estrogen period. This was unaccompanied by any significant difference between periods in respect of water balance, or of urinary $\mathrm{Cl}, \mathrm{Na}$ or $\mathrm{K}$ output. The decrease in plasma protein concentration was of the same order as in the normal group. The small differences observed in plasma $\mathrm{Cl}$ and $\mathrm{Na}$ concentration were within the experimental error of the methods.

In case $68, a \mathrm{NaCl}$ and water diuresis occurred spontaneously at bed rest. Weight showed a rapid decline during the control period, and levelled off during the estrogen period. The significant differences between periods observed in water balance and urinary $\mathrm{Cl}$ and $\mathrm{Na}$ outputs are due to the gradual cessation of diuresis during the estrogen period. There was no significant change in urinary $\mathrm{K}$ output, nor in total serum protein or plasma $\mathrm{Cl}$ and $\mathrm{Na}$ levels. The failure of estrogen administration to affect significantly the $\mathrm{NaCl}$ and water diuresis in this case is in contrast to the effect on case 53 (constrictive pericarditis), and on other cases (1) where a similar diuresis was reversed by estrogen.

\section{Nephrotic syndrome (Table II)}

Weight. Group analysis was not attempted because of the relatively large proportion of trends in the control period. There was a tendency to 
decrease weight following estrogen administration in cases 37,51 and 57 . In case 54 , there was no significant change, but in case 30 a significant increase occurred.

Water balance. There was no significant group mean difference between periods. There was similarly no significant difference in any case, except in case 30 , where the difference of $+260 \mathrm{ml}$. was significant. A decrease of borderline significance was observed in case 57.

Daily urinary outputs. $\mathrm{Cl}$ and $\mathrm{Na}$. Group mean differences between periods were not significant. No significant change was observed in any individual case, except in No. 30 where there was a significant decrease in $\mathrm{Cl}$ and $\mathrm{Na}$ output following estrogen.

$K$. Group mean difference between periods was not significant. There was no significant difference between periods in any individual case.

$P O_{4}$. This estimation was done in two cases only. A small but significant difference was observed in case $30(\bar{d}=-7 \mathrm{mEq} ., P=0.01)$, but there was no significant difference in case 37 .

Total serum protein. No significant difference between periods was observed.

Venous hematocrit. There was a highly significant difference in volume of packed cells following estrogen administration, $\overline{\mathrm{d}}=-4$ per cent, $P=0.01$. This represents a mean decrease of 10 per cent below the mean control value.
Plasma $\mathrm{Cl}$ and $\mathrm{Na}$. There was no significant difference between periods, $\bar{d}=-0.4 \mathrm{mEq}$. per L. $\mathrm{Cl}$, and $-2 \mathrm{mEq}$. per L. $\mathrm{Na}, \mathrm{P}=0.8$ and 0.06 respectively.

Thiocyanate space. This observation was made in three cases only, Nos. 37, 51 and 54. There was an increase in the space in each case of between 0.5 and $1.0 \mathrm{~L}$. This increase is of the same order as that found in the normal group.

Figure 4 shows that there was no marked alteration in the rate of gain in average weight during the estrogen period, and that there was no sustained effect on average sodium output, or on water balance. The urinary $\mathrm{Na} / \mathrm{Cl}$ ratios likewise showed no significant change during the estrogen period.

By calculation, relatively small amounts of $\mathrm{Cl}$, $\mathrm{Na}$ and water were apparently retained during the estrogen period, the mean figures being $88 \mathrm{mEq}$. $\mathrm{Cl}, 36 \mathrm{mEq}$. $\mathrm{Na}$, and $330 \mathrm{ml}$. water. There was a mean increase in weight of $0.6 \mathrm{~kg}$., taken from the last day of the control period. These figures are not in the expected proportion, had the changes been chiefly due to increased ECF volume.

\section{Low plasma protein edema (Table II)}

Group analysis was not attempted. In case 69, a small increase of weight during the estrogen period was of borderline significance. This was accompanied by a significant increase in water balance, but no corresponding changes in urinary out-

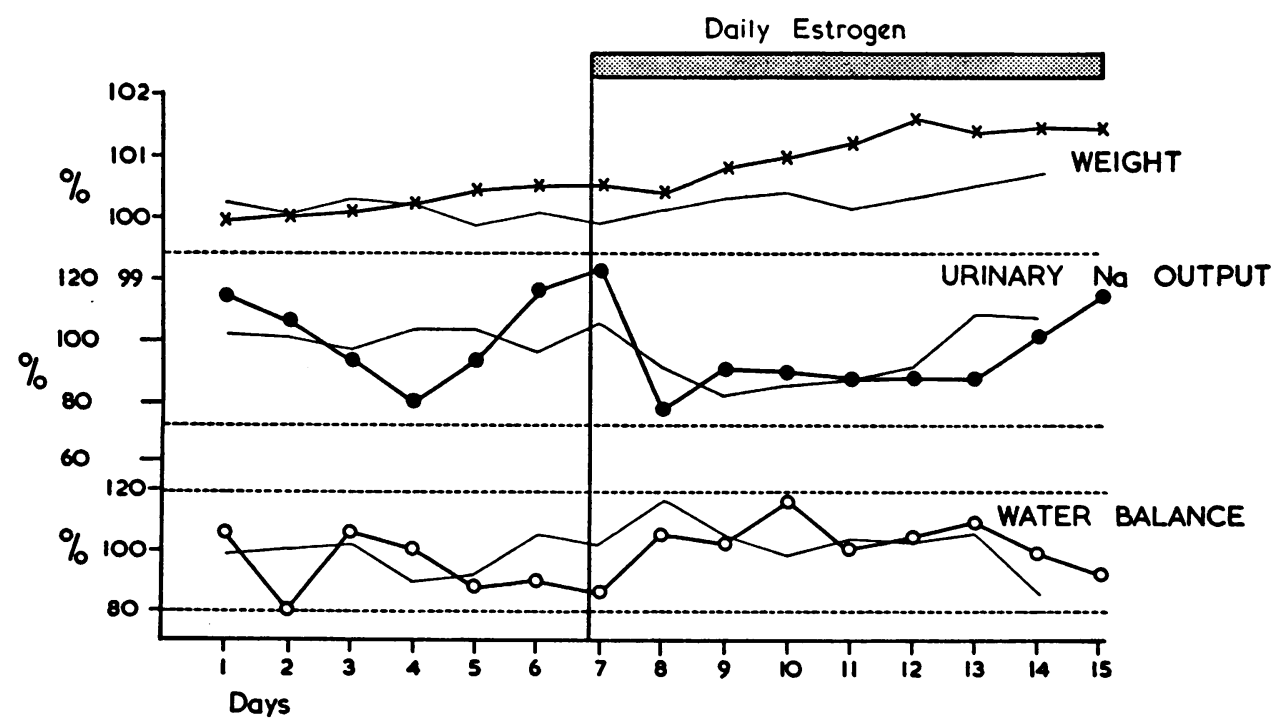

Fig. 4. The Effect of Estrogen Administration on Daily Weight, Urinary Sodium Output and Water Balance in the Nephrotic Syndrome

See footnote, Figure 1. 
put of $\mathrm{Cl}, \mathrm{Na}$ or $\mathrm{K}$. No significant alterations in the levels of plasma $\mathrm{Cl}$ and $\mathrm{Na}$, or of total serum protein.

In case 77 , there was a significant increase of weight, but no significant change in water balance, or urinary $\mathrm{Cl}, \mathrm{Na}$ or $\mathrm{K}$ output. Plasma $\mathrm{Cl}$ and $\mathrm{Na}$ levels were unaltered, but there was a significant increase in total serum protein, associated with an adequate dietary intake while in hospital.

\section{DISCUSSION}

In the group of constrictive pericarditis the administration of estrogen was associated with marked and sustained retention of $\mathrm{Cl}, \mathrm{Na}$ and water (Table I and Figures 1 and 4). Similar results were also observed in the group of cardiac failure, although to a less degree (Table 1 and Figures 2 and 3 ). Both observations are in significant contrast to the slight and transient effects on $\mathrm{NaCl}$ and water metabolism seen in the normal.

In the group of nephrotic cases (Table II, and Figures 3 and 4) the effect of estrogen on $\mathrm{NaCl}$ and water metabolism did not differ from the normal as a group. In four of the five individual cases, there was no evidence of $\mathrm{NaCl}$ and water retention, but in one case (No. 30) definite retention did occur. This case differed from the remainder in that the nephrotic syndrome had been present for 5 to 6 years as opposed to a maximum of 18 months in the other cases. The $\mathrm{NaCl}$ and water retention in this case is unlikely to be due to lowered plasma albumen levels, since there was no indication of abnormal retention in the two cases of low plasma protein edema, following estrogen (Table II).

The failure to find significant retention of $\mathrm{NaCl}$ and water in the nephrotic group is of particular interest, since there are two features in common between this group and the groups of constrictive pericarditis and cardiac failure, namely an existing tendency to fluid retention, and a reduction in renal clearance rates $(3-6)$. This observation indicates that the kidney plays no primary role in the $\mathrm{NaCl}$ and water retention after estrogen administration.

In view of the above findings, and since involvement of the liver is the only factor common to all groups in which fluid retention after estrogen occurred and absent from all groups in which such fluid retention did not occur (1), it seems likely that the factor deciding this fluid retention is hepatic. Furthermore, it seems reasonable to suppose that this hepatic factor is impaired inactivation of the hormone.

In both constrictive pericarditis and cardiac failure due to other causes, the hepatic circulation is prominently affected. There is increased hepatic vein pressure and sinusoidal congestion $(5,7,8)$. Where cardiac output is low in cardiac failure of various etiologies, hepatic blood flow is reduced in proportion (7). Although hepatic blood flow has not been specifically studied in constrictive pericarditis, cardiac output and renal blood flow are reduced (5) and it is reasonable to assume that hepatic blood flow is reduced also.

Hepatic biopsy studies $(8,9)$ indicate that although hepatocellular necrosis and atrophy may occur in cardiac failure, these changes are never so extensive as to lead to hepatocellular failure (as in portal hepatic cirrhosis). These histological changes closely parallel the clinical severity and duration of the cardiac failure, and are, moreover, reversible, healing taking place when the failure is brought under control.

In our group of constrictive pericarditis, four of the cases were early and asymptomatic, and hepatocellular damage may therefore be presumed minimal. This was in fact demonstrated in two (Nos. 52 and 59) of these four cases by hepatic biopsy. Even in one of the more severe cases (No. 46), structural changes were also found to be minimal. In the cardiac failure group, no hepatic biopsies were performed, but two cases (Nos. 32 and 47) were recovering from first and clinically mild attacks of failure, and in these hepatocellular damage was again presumably minimal.

It is significant that the marked $\mathrm{NaCl}$ and water retention observed in these two groups after estrogen was not confined to the more advanced cases or to cases with existing edema or ascites, but occurred also in three of the four early asymptomatic cases of constrictive pericarditis and in both early cases of cardiac failure (Tables I and II).

These observations, together with those already described, provide good evidence that fluid retention after estrogen is greatly dependent upon impaired hepatic circulation. Strong support is therefore provided for the hypothesis that differ- 
ing degrees of hepatic circulatory impairment leading to differing rates of estrogen inactivation, may be responsible for the marked fluid retention in cirrhosis with ascites, as contrasted with the slight retention in cirrhosis without ascites, after the administration of estrogen (1).

Furthermore, since our results demonstrate that exogenous estrogen can cause fluid retention in the above groups, it becomes possible that endogenous estrogen may have a similar affect. Increased estrogen activity may, therefore, be a factor in the naturally-occurring fluid retention, not only of constrictive pericarditis, but of any form of cardiac failure where the hepatic circulation is permanently affected.

The above observations do not however, exclude the action of other Na-retaining hormones, and the finding of a sodium-retaining factor resembling aldosterone in the urine of cases of hepatic cirrhosis (10) and cardiac failure (11) suggests that this hormone is also involved.

The actual role of aldosterone in the fluid retention of these conditions remains to be determined. Increased aldosterone excretion appears to be related rather to low urinary $\mathrm{Na}$ levels than to the disease process or state of hydration (11). Since control urinary $\mathrm{Na}$ levels in our cases were either within the normal range or high, it would appear that fluid retention after estrogen is not dependent on an existing high degree of aldosterone activity. In addition, the fluid-retaining effect of estrogen has been shown in our studies to be closely if not exclusively, related to hepatic involvement by disease, whereas urinary aldosterone is markedly increased in nephrosis and in normal subjects on a low-Na diet (11), where the liver is presumably healthy. It would appear, therefore, on the evidence at present available, that fluid retention after estrogen administration may be independent of aldosterone.

\section{SUM MARY}

1. Daily administration of estradiol caused marked $\mathrm{NaCl}$ and water retention in cases of constrictive pericarditis, and in cardiac failure of other origin, but not in two cases of peripheral venous obstruction.

2. The same dosage of estradiol caused no significant $\mathrm{NaCl}$ and water retention in a group with the nephrotic syndrome, nor in two cases of low plasma albumin edema without renal disease.

3. These findings indicate that the $\mathrm{NaCl}$ and water retention following estrogen administration is dependent mainly upon disturbances of the hepatic circulation, and that the kidney plays no primary role.

4. This evidence supports the hypothesis that the quantitative difference observed between the fluid retention of cirrhosis with ascites and that of cirrhosis without ascites following estrogen administration may be accounted for by hepatic circulatory factors.

5. It is further suggested that increased estrogen activity may be a factor in the fluid retention of cases of cardiac failure in which the hepatic circulation is prominently affected.

\section{REFERENCES}

1. Preedy, J. R. K., and Aitken, E. H., The effect of estrogen on water and electrolyte metabolism. II. Hepatic disease. J. Clin. Invest., 1956, 35, 430.

2. Preedy, J. R. K., and Aitken, E. H., The effect of estrogen on water and electrolyte metabolism. I. The normal. J. Clin. Invest., 1956, 35, 423.

3. Earle, D. P., Jr., Taggart, J. V., and Shannon, J. A., Glomerulonephritis. A survey of the functional organization of the kidney in various stages of diffuse glomerulonephritis. J. Clin. Invest., 1944, 23, 119.

4. Bradley, S. E., Bradley, G. P., Tyson, C. J., Curry, J. J., and Blake, W. D., Renal function in renal diseases. Am. J. Med., 1950, 9, 766.

5. McKusick, V. A., Chronic constrictive pericarditis. I. Some clinical and laboratory observations. Bull. Johns Hopkins Hosp., 1952, 90, 3.

6. Smith, H. W., The Kidney. Structure and Function in Health and Disease. New York, Oxford University Press, 1946, pp. 666-673.

7. Myers, J. D., and Hickam, J. B., An estimation of the hepatic blood flow and splanchnic oxygen consumption in heart failure. J. Clin. Invest., 1948, 27, 620.

8. Sherlock, S., The liver in heart failure. Relation of anatomical, functional, and circulatory changes. Brit. Heart J., 1951, 13, 273.

9. Wallach, H. F., and Popper, H., Central necrosis of the liver. Arch. Path., 1950, 49, 33.

10. Chart, J. J., and Shipley, E. S., The mechanism of sodium retention in cirrhosis of the liver. J. Clin. Invest., 1953, 32, 560.

11. Luetscher, J. A., Jr., and Johnson, B. B., Observations on the sodium-retaining corticoid (aldosterone) in the urine of children and adults in relation to sodium balance and edema. J. Clin. Invest., 1954, 33, 1441. 